\title{
Novel thermoplastic vulcanizates (TPVs) based on silicone rubber and polyamide exploring peroxide cross-linking
}

\author{
T. Chatterjee ${ }^{1,2}$, S. Wiessner ${ }^{1,3}$, K. Naskar ${ }^{2 *}$, G. Heinrich ${ }^{1,3}$ \\ ${ }^{1}$ Leibniz-Institut für Polymerforschung Dresden e.V., Hohe Strasse 6, D-01069 Dresden, Germany \\ ${ }^{2}$ Rubber Technology Centre, Indian Institute of Technology, Kharagpur, 721302 Kharagpur, West Bengal, India \\ ${ }^{3}$ Technische Universität Dresden, Institut für Werkstoffwissenschaft, D-01062 Dresden, Germany
}

Received 10 September 2013; accepted in revised form 19 November 2013

\begin{abstract}
Novel thermoplastic vulcanizates (TPVs) based on silicone rubber (PDMS) and polyamide (PA12) have been prepared by dynamic vulcanization process. The effect of dynamic vulcanization and influence of various types of peroxides as cross-linking agents were studied in detail. All the TPVs were prepared at a ratio of 50/50 wt $\%$ of silicone rubber and polyamide. Three structurally different peroxides, namely dicumyl peroxide (DCP), 3,3,5,7,7-pentamethyl 1,2,4-trioxepane (PMTO) and cumyl hydroperoxide (CHP) were taken for investigation. Though DCP was the best option for curing the silicone rubber, at high temperature it suffers from scorch safety. An inhibitor 2,2,6,6-tetramethylpiperidinyloxyl (TEMPO) was added with DCP to stabilize the radicals in order to increase the scorch time. Though CHP (hydroperoxide) had higher half life time than DCP at higher temperature, it has no significant effect on cross-linking of silicone rubber. PMTO showed prolonged scorch safety and better cross-linking efficiency rather than the other two. TPVs of DCP and PMTO were made up to 11 minutes of mixing. Increased values of tensile strength and elongation at break of PMTO cross-linked TPV indicate the superiority of PMTO. Scanning electron micrographs correlate with mechanical properties of the TPVs. High storage modulus $\left(E^{\prime}\right)$ and lower loss tangent value of the PMTO cross-linked TPV indicate the higher degree of cross-linking which is also well supported by the overall cross-link density value. Thus PMTO was found to be the superior peroxide for cross-linking of silicone rubber at high temperature.
\end{abstract}

Keywords: polymer blends and alloys, thermoplastic vulcanizate, silicone rubber (PDMS), polyamide (PA12) and peroxides

\section{Introduction}

Blending of polymers is a smart and economical strategy for obtaining new and improved polymeric materials from the existing polymers, which are difficult to obtain by direct polymerization process $[1,2]$. Even though more than 400 miscible polymer pairs have been reported [3, 4], most of them are not miscible on a molecular scale and tend to undergo phase separation during mixing. Numerous rubber-plastic blends are available, only few of them are commercially attractive because of compatibility between the components. Thermoplastic elastomers (TPEs) are a class of polymers or polymer blends that have rubber-like behaviour, but can be melt-processed like thermoplastic polymers $[5,6]$. The combination of these properties is obtained by the two-phase structure of the materials: the soft phase, an elastomer, gives the rubber-like properties in the solid state, whereas the hard phase, a thermoplastic polymer with high glass transition temperature, gives strength to the blend. At the temperature of utilization, the latter is the stiffer phase that acts as physical crosslinker for the elastomer phase. At elevated temperatures (above the glass transition temperature or above the melting point), the hard phase softens and the TPE becomes processable.

\footnotetext{
*Corresponding author, e-mail: knaskar@rtc.iitkgp.ernet.in (C) BME-PT
} 
Thermoplastic vulcanizates (TPVs) are a highly engineered class of thermoplastic elastomers, comprising a cross-linked elastomeric phase and a melt processable thermoplastic phase. These materials are produced by dynamic vulcanization process, in which both mixing and cross-linking are carried out at the same time in a melt mixing device. Resulting compound exhibits more elastomer-like properties: such as lower compression set, lower stiffness, greater resistance to fatigue, heat and chemicals than the corresponding rubber or plastic $[7,8]$. The dynamic vulcanization process was first reported by Gessler and Haslett [9] in 1962 and then further developed by Fischer [10] by his early work on polypropylene (PP)/ethylene propylene diene rubber (EPDM) TPVs with peroxides as cross-linking agent, resulted in the commercialization of 'Uniroyal TPR' thermoplastic rubber. Greater industrial attention was generated only after extensive study of TPVs based on various blend components by Coran and Patel in the 1980s [11, 12]. They performed extensive studies on PP and EPDM blends that were dynamically vulcanized with high crosslink density in the rubber phase. These works led to the commercialization of 'Santoprene' TPE, which was introduced by Monsanto in 1981. Most commercial TPVs are based on heterogeneous blends of PP and ethylene-propylene-diene rubber (EPDM) because of their structural compatibility. Naskar and Noordermeer $[13,14]$ extensively studied the influence of different peroxides and multifunctional peroxide in the conventional PP/EPDM blends. Later Naskar et al. [15] also developed a novel PP/EPDM TPV by electron induced reactive processing. Further TPVs based on silicone rubber [16] and maleated ethylene propylene rubber (EPM) [17] was also developed for some special purpose. Babu and coworkers $[18,19]$ explored a new TPV based on polypropylene (PP) and ethylene octene copolymer (EOC) blend system. EOC has gained special attention because of its unique molecular structure and also it provides better toughening characteristics than EPDM rubber [20, 21]. Recently Giri et al. [22] developed a new system in this family which is based on LLDPE/ PDMS blend system. But all the TPVs have limited use in automotive applications due to their low heat resistance and poor oil resistance properties associated with the olefinic thermoplastic matrices [23]. To fulfill these two requirements a new family of high performance TPV called 'super TPV', based on cross-linked silicone rubber particles dispersed in a variety of engineering thermoplastic matrix, was developed by Dow Corning [24]. In this present investigation polyamide (PA12) and silicone rubber (PDMS) are of special interest and a new super TPV system with a blend ratio of $50 / 50 \mathrm{wt} \%$ has been developed.

Silicone rubber (PDMS) is notable for its unique characteristics: such as very low $T_{\mathrm{g}}\left(-125^{\circ} \mathrm{C}\right)$ due to highly flexible [O-Si-O] backbone, very wide service temperature range, good aging properties, resistance to UV radiation, low toxicity, hydrophobic and physiologically inert [25-27]. Tensile strength of silicone rubber is very low and its oil and solvent resistance properties are also very poor [28]. To overcome these drawbacks of silicone rubber, a new blend system of silicone rubber (PDMS) and polyamide (PA12) has been chosen for the development of a novel TPV with controlled properties. PA12 has excellent solvent and oil resistance, in particular acid and alkali resistance and excellent environmental stress cracking resistance at elevated temperature [29]. Cross-linking of the PDMS rubber phase by organic peroxides suffers from scorching problems at high mixing temperature due to the faster decomposition of the peroxides (normally used for curing) [30,31]. To overcome this difficulty three structurally different peroxides, namely dicumyl peroxide (DCP), 3,3,5,7,7-pentamethyl 1,2,4-trioxepane (PMTO) and cumyl hydroperoxide (CHP) were chosen for investigation. It is reported earlier that, though DCP was the best option for curing the silicone rubber, at high temperature it suffers from scorch safety since it has a typical crosslinking temperature at $160^{\circ} \mathrm{C}$. At higher temperatures above $180^{\circ} \mathrm{C}$ it has very low half life time $\left(t_{1 / 2}\right)$. An inhibitor 2,2,6,6-tetramethylpiperidinyloxyl (TEMPO) was added with DCP to increase the scorch safety by scavenging the peroxide radicals $[31,32]$. The main objective of this present work is to develop of a novel high performance TPV based on a PDMS/ PA12 blend system at 50:50 blends ratio using different peroxides with suitable decomposition kinetics as the cross-linking agent to induce dynamic vulcanization of the PDMS phase. After that the morphological characteristics, mechanical properties, dynamic mechanical analysis, rheological and thermal properties of all the TPV systems were pursued to get a better insight. 


\section{Experimental}

\subsection{Materials}

Polydimethyl siloxane (PDMS) (which trade name is XIAMETER RBB-2140-50) was procured from Dow Corning, USA. It has a Mooney viscosity, $M L_{(1+4)}$ at $100^{\circ} \mathrm{C}$ of 30 and density at $25^{\circ} \mathrm{C}$ of $1.15 \mathrm{gm} / \mathrm{cm}^{3}$. Polyamide 12 (PA12) (Rilsan ${ }^{\circledR}$ AESNO TL) was procured from Arkema, France. It has the density at $25^{\circ} \mathrm{C}$ of $1.02 \mathrm{gm} / \mathrm{cm}^{3}$. The melt flow rate of PA12, measured at $190^{\circ} \mathrm{C}$ and $2.16 \mathrm{~kg}$ load is $0.646 \mathrm{gm} / 10 \mathrm{~min}$. Main characteristics of these polymeric materials are reported in the Table 1.

Cross-linker: Three structurally different organic peroxides were used for the cross-linking of the PDMS as follows: i) Perkadox BC-FF, Dicumyl peroxide (DCP); ii) Trigonox 311-50D (PMTO); iii) Trigonox K-90, Cumyl hydroperoxide (CHP). All of them were procured from Akzo Nobel, Netherlands. Their commercial names, chemical names, chemical structures and molecular characteristics are given in Table 2 .

Nitroxide 2,2,6,6-tetramethylpiperidinyloxyl (TEMPO) procured from Aldrich Chemicals, was used as an inhibitor, in conjunction with DCP to control the scorch during mixing. The concentration of TEMPO was calculated in order to provide a molar ratio of ([TEMPO]/[DCP] $=1.6)[31,32]$.

\subsection{Mixing}

To understand the curing characteristics of the three peroxides, the mixing of different peroxides with PDMS was performed in a laboratory kneader type

Table 1. Characteristics of the raw materials

\begin{tabular}{|c|c|c|c|c|c|}
\hline Material & Trade name & $\begin{array}{c}\mathbf{T}_{\mathbf{g}} \\
{\left[{ }^{\circ} \mathbf{C}\right]}\end{array}$ & $\begin{array}{c}\mathbf{T}_{\mathbf{m}} \\
{\left[{ }^{\circ} \mathbf{C}\right]}\end{array}$ & $\begin{array}{c}\text { Tensile strength } \\
{[\mathbf{M P a}]}\end{array}$ & $\begin{array}{c}\text { Tensile elongation at break } \\
{[\%]}\end{array}$ \\
\hline Silicone rubber & $\begin{array}{c}\text { XIAMETER } \\
\text { RBB-2140-50 }\end{array}$ & -124 & - & 0.8 & 465 \\
\hline $\begin{array}{c}\text { Polyamide } \\
\text { (PA12) }\end{array}$ & $\begin{array}{c}\text { Rilsan } \\
\text { AESNO TL }\end{array}$ & 55 & 177 & 68.9 & 330 \\
\hline
\end{tabular}

Table 2. Commercial name, chemical name and molecular characteristics of the three different peroxides

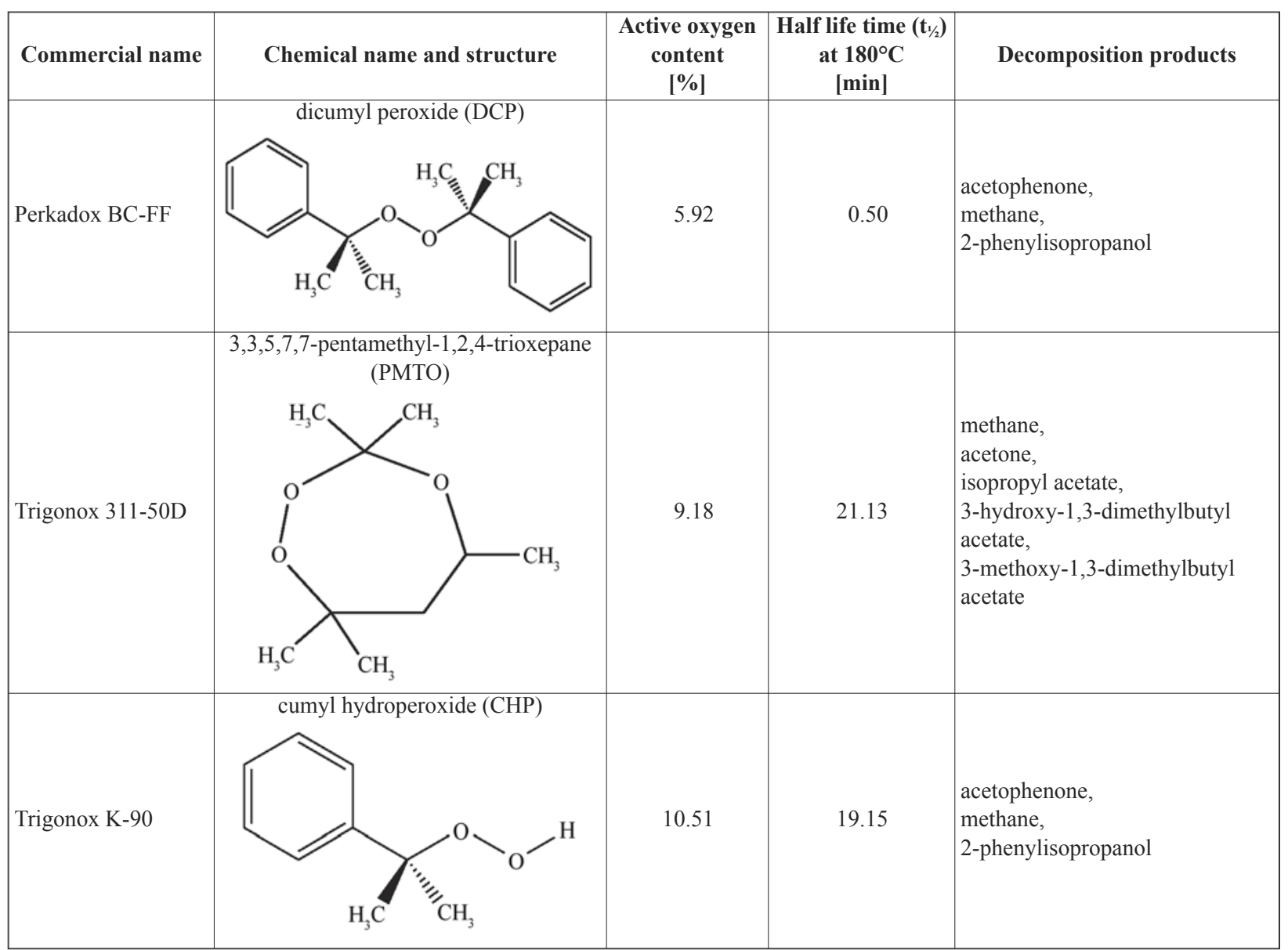


W30 EHT Brabender, Germany, having a free volume of $30 \mathrm{~cm}^{3}$ fitted with two counter-rotating rotors. Peroxides were mixed with PDMS at $40^{\circ} \mathrm{C}$ and at a rotor speed of $60 \mathrm{rpm}$. All the blends of silicone rubber (PDMS) and polyamide (PA12) at a blend ratio of 50:50 (wt\%) were also prepared in a batch process using the same instrument at a rotor speed of $120 \mathrm{rpm}$. According to literature though polyamide has the melting point in the range of $180^{\circ} \mathrm{C}$, but it has been seen that polyamide did not melt at $180^{\circ} \mathrm{C}$ even after 12 minutes mixing. For that reason mixing was performed at $190^{\circ} \mathrm{C}$. The mixer was connected to a drive unit Plastograph, which allows using of integrated pendulum dynamometer to detect the torque during compounding. The temperature development in the mixed material is measured by an integrated gusset at the bottom region of the mixing chamber thermocouple. Temperature control of the mixing chamber, front and rear plate was done via integrated thermocouples. Using a mass temperature sensor and a self-aligning dynamometer, which detects the torque, a torque-temperature diagram in function of time is created.

For the reactive blending at first, peroxides $(1 \mathrm{wt} \%)$ were premixed with PDMS at the room temperature before its addition to the molten PA12. For dicumyl peroxide (DCP), TEMPO was added with DCP to increase the scorch safety. At first PA12 was poured into the mixing chamber at $190^{\circ} \mathrm{C}$ and at $120 \mathrm{rpm}$ and was allowed for melting. After melting of the PA12 matrix, PDMS (premixed with peroxide) was added to the molten thermoplastic phase. Finally TPVs were developed with $(50 / 50) \mathrm{wt} \%$ of PDMS and PA12 at a rotor speed of $120 \mathrm{rpm}$ at $190^{\circ} \mathrm{C}$ using 11 minutes of mixing. Then the samples were injection moulded from a micro-injection moulding machine at $250^{\circ} \mathrm{C}$ and 7 bar pressure. Testing was performed after 24 hour of maturation.

\subsection{Testing procedure}

\subsubsection{Curing characteristics}

Curing characteristics of the different peroxide mixed PDMS were determined from Göttfert Elastograph Vario 67.03, Germany. From this the optimum curing time as well as scorch time of PDMS for various peroxides was determined. Testing conditions were maintained at $180^{\circ} \mathrm{C}$ for 60 minutes and at a frequency of $1.67 \mathrm{~Hz}$. The rotational angle of the disk was $5^{\circ}$.

\subsubsection{Morphology study}

The morphological study of final TPV samples and dispersion of PDMS and PA12 phase was carried out using a Scanning Electron Microscope (LEO 435 VP, Carl Zeiss SMT, Jena, Germany). At first, the sample was taken over a sticky surface made by conductive carbon cement on a SEM sample holder. After that the samples were cut with the ultramicrotome UC 7, Leica, Wetzlar, Germany and then it is platinum coated (layer thickness $15 \mathrm{~nm}$ ) using a sputter coater (BAL-TEC SCD 500 Sputter Coater). The morphology has been characterized by energy dispersive X-ray spectroscopy (EDX) via mapping of carbon, silicon, nitrogen, oxygen distribution in the sample. EDX delivers information about morphology without etching. Morphology study of the TPVs was also carried out by atomic force microscope (Bruger, Icon, Germany). Testing has been performed in the tapping mode. Tip stiffness was $40 \mathrm{~N} / \mathrm{m}$ and tip radius was $10 \mathrm{~nm}$.

\subsubsection{Mechanical properties}

Tensile tests were carried out according to DIN $53504 / \mathrm{S} 2 / 50$ on dumb-bell shaped specimens using an universal tensile testing machine Zwick Z010 at a constant cross-head speed of $50 \mathrm{~mm} / \mathrm{min}$. $E$-modulus was determined in between 0.20 to $0.40 \%$ of strain.

\subsubsection{Dynamic mechanical thermal analysis (DMTA)}

Dynamic mechanical thermal analysis (DMTA) of the samples was carried out using an Eplexor 150N DMTA (Gabo Qualimeter, Ahlden, Germany). Tests were carried out at a frequency of $10 \mathrm{~Hz}$ under static strain of $0.50 \%$ and dynamic strain of $0.10 \%$. The samples were first cooled to $-150^{\circ} \mathrm{C}$ and then subsequently heated at a rate of $3 \mathrm{~K} / \mathrm{min}$ over a range of temperature from -150 to $200^{\circ} \mathrm{C}$.

\subsubsection{Thermogravimetric analysis (TGA)}

Thermogravimetric analysis (TGA) and derivative thermogravimetry (DTG) of the neat components and the blends of PDMS/PA12 was measured by using a thermogravimetric analyzer (TGA Q5000, TA Instruments, USA) at a heating rate of $10 \mathrm{~K} / \mathrm{min}$ under nitrogen atmosphere. 


\subsubsection{Melt rheological study}

The rheological measurements of silicone rubber and polyamide were carried out by an Advanced Rheometric Expansion System (ARES) rheometer (Rheometric Scientific Inc, USA). The torque transducer had a torque range from 0.02 to $2000 \mathrm{~g} \cdot \mathrm{cm}$. Parallel plate geometry was applied to the formerly pressed plates with $2 \mathrm{~mm}$ thickness and $25 \mathrm{~mm}$ diameter. Frequency range was selected between 0.1 to $100 \mathrm{rad} / \mathrm{s}$ and strain controlled dynamic frequency sweep test was applied. The measurements were done in $\mathrm{N}_{2}$ atmosphere at a temperature of $190^{\circ} \mathrm{C}$. During each experiment, the temperature maintained at the desired value by constant heating of the sample under nitrogen atmosphere.

\subsubsection{Overall cross-link density}

The overall crosslink density of silicone rubber was determined on the basis of equilibrium solventswelling measurements in toluene by the application of the well-known Flory-Rehner equation at room temperature (Equation (1)):

$$
(\nu+P A)=-\frac{1}{V_{\mathrm{S}}} \cdot \frac{\ln \left(1-V_{\mathrm{r}}\right)+V_{\mathrm{r}}+\chi V_{\mathrm{r}}^{2}}{\left(V_{\mathrm{r}}\right)^{1 / 3}-0.5 V_{\mathrm{r}}}
$$

where $v$-number of moles of effectively elastic chains per unit volume of PDMS [mol/ml] (crosslink density), $P A-\mathrm{PA} 12, V_{\mathrm{s}}$ - molar volume of solvent (toluene) [cc/mol], which is $105.74 \mathrm{cc} / \mathrm{mol}, \chi-$ polymer-swelling agent interaction parameter, taken as 0.45 for both PDMS and toluene at $20^{\circ} \mathrm{C}$ [33], $V_{\mathrm{r}}$ - volume fraction of rubber in the swollen network and $V_{\mathrm{r}}$ can be expressed as Equation (2):

$$
V_{\mathrm{r}}=\frac{1}{A_{\mathrm{r}}+1}
$$

where $A_{\mathrm{r}}$ - ratio of the volume of absorbed toluene to that silicone after swelling.

\section{Results and discussion}

\subsection{Curing characteristics}

Cure curves of PDMS cross-linked by different peroxides $(1 \mathrm{wt} \%)$ at $180^{\circ} \mathrm{C}$ are shown in Figure 1.

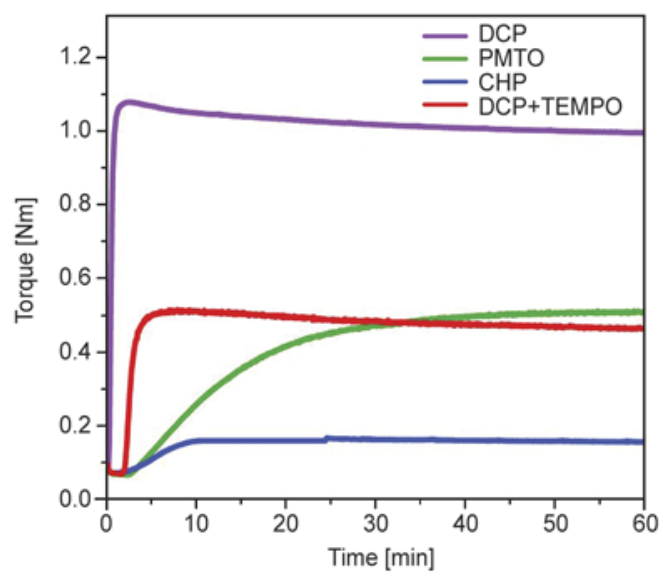

Figure 1. Cure curves of PDMS by different peroxides $(1 \%)$ at $180^{\circ} \mathrm{C}$

From the cure curve it is clear that at $180^{\circ} \mathrm{C}, \mathrm{DCP}$ itself is faster curing peroxide for PDMS than PMTO and CHP. Scorch safety time $\left(t_{2}\right)$, optimum curing time $\left(t_{90}\right)$, maximum torque and delta torque values for the three different peroxides are given in the Table 3. From Table 3 it can be observed that at $180^{\circ} \mathrm{C}$, scorch safety time and optimum curing time of PDMS for DCP is 0.33 and 0.90 minutes respectively. On the other hand, after using TEMPO, though scorch safety time and optimum curing time of PDMS for DCP were found to increase the crosslinking efficiency becomes lower which is clear from the Figure 1. From Table 3 it can be seen that maximum torque value for (DCP+TEMPO) comes down to $0.541 \mathrm{Nm}$ which is near to half of the torque value (1.079 Nm) of DCP only, whereas the optimum curing time of (DCP+TEMPO) becomes 4.18 minute which is five times ( 0.90 minute) more than that of DCP only. It indicates that by using TEMPO the scorch safety time can be increased while the crosslinking efficiency of the peroxide would be reduced at the same time.

From Figure 1 it can be noticed that at $180^{\circ} \mathrm{C}$ PMTO is very slow curing peroxide for the PDMS and its state of cure is also poor. Optimum curing time of PDMS for PMTO is 28.20 minutes which is much higher than that of DCP. For CHP, though the optimum curing time is 18.20 minutes, higher than DCP,

Table 3. Curing characteristics of PDMS by three different peroxides at $180^{\circ} \mathrm{C}$

\begin{tabular}{|l|c|c|c|c|c|}
\hline \multicolumn{1}{|c|}{ Peroxides } & $\begin{array}{c}\mathbf{t}_{\mathbf{2}} \\
{[\mathbf{m i n}]}\end{array}$ & $\begin{array}{c}\mathbf{t}_{\mathbf{9 0}} \\
{[\mathbf{m i n}]}\end{array}$ & $\begin{array}{c}\text { Minimum torque } \\
{[\mathbf{N m}]}\end{array}$ & $\begin{array}{c}\text { Maximum torque } \\
{[\mathbf{N m}]}\end{array}$ & $\begin{array}{c}\text { Delta torque } \\
{[\mathbf{N m}]}\end{array}$ \\
\hline DCP & 0.33 & 0.90 & 0.088 & 1.079 & 0.991 \\
\hline DCP+TEMPO & 1.80 & 4.18 & 0.076 & 0.541 & 0.465 \\
\hline PMTO & 4.50 & 28.20 & 0.066 & 0.512 & 0.446 \\
\hline CHP & 3.80 & 18.20 & 0.073 & 0.168 & 0.095 \\
\hline
\end{tabular}


Table 4. Curing characteristics of PDMS by three different peroxides at $200^{\circ} \mathrm{C}$

\begin{tabular}{|l|c|c|c|c|c|}
\hline \multicolumn{1}{|c|}{ Peroxides } & $\begin{array}{c}\mathbf{t}_{\mathbf{2}} \\
{[\mathbf{m i n}]}\end{array}$ & $\begin{array}{c}\mathbf{t}_{\mathbf{9 0}} \\
{[\mathbf{m i n}]}\end{array}$ & $\begin{array}{c}\text { Minimum torque } \\
{[\mathbf{N m}]}\end{array}$ & $\begin{array}{c}\text { Maximum torque } \\
{[\mathbf{N m}]}\end{array}$ & $\begin{array}{c}\text { Delta torque } \\
{[\mathbf{N m}]}\end{array}$ \\
\hline DCP+TEMPO & $0.40=24 \mathrm{~s}$ & $1.11=66 \mathrm{~s}$ & 0.068 & 0.502 & 0.434 \\
\hline PMTO & $1=60 \mathrm{~s}$ & $7.80=468 \mathrm{~s}$ & 0.063 & 0.515 & 0.452 \\
\hline
\end{tabular}

but the maximum torque is $0.168 \mathrm{Nm}$ only. On the other hand, from Table 3, it can be observed that the delta torque values for (DCP+TEMPO) and PMTO are $0.465 \mathrm{Nm}$ and $0.446 \mathrm{Nm}$ respectively whereas for CHP the delta torque value is $0.095 \mathrm{Nm}$ only. This clearly implies, though CHP gives better scorch safety than DCP but its cross-linking efficiency is very poor. It means $\mathrm{CHP}$ is not the suitable peroxide for the cross-linking of PDMS. Curing characteristics of peroxide mixed PDMS at $200^{\circ} \mathrm{C}$ has been given in Table 4. From Table 4 it can be observed that curing characteristics of peroxide mixed PDMS follow the same trend. Only time has become $1 / 4^{\text {th }}$ at $200^{\circ} \mathrm{C}$. On the other side the curing characteristics of (DCP+TEMPO) and PMTO are comparable. Therefore, for the next part of the study (DCP+ TEMPO) and PMTO have been pursued to develop and characterize the corresponding TPVs.

\subsection{Mixing curve}

Table 5 demonstrates the formulation of the TPVs which have been studied in this investigation. Mixing curves of the TPVs of PDMS and PA12 have been shown in Figure 2. From this, it can be observed that cross-linking efficiency of (DCP+TEMPO) is higher initially than that of PMTO as it shows very low scorch safety and low optimum curing time. On the other hand, cross-linking efficiency of PMTO is little bit less than (DCP+TEMPO), but it gives much better scorch safety during the preparation of TPV. Therefore, in (DCP+TEMPO) cross-linked TPV torque raises maximum but due to faster decomposition of DCP the rate of fall of torque is also very rapid and within one minute torque has fallen down from $31.56 \mathrm{Nm}$ down to $19.31 \mathrm{Nm}$. As a result poor

Table 5. Detailed description of the TPVs made from PDMS/PA12 by different peroxides

\begin{tabular}{|l|c|c|c|}
\hline \multicolumn{1}{|c|}{ Sample code } & $\begin{array}{c}\text { PDMS } \\
{[\mathbf{w t} \%]}\end{array}$ & $\begin{array}{c}\text { PA12 } \\
{[\mathbf{w t} \%]}\end{array}$ & Peroxides \\
\hline Si_PA_D_T & 50 & 50 & DCP+TEMPO \\
\hline Si_PA_P & 50 & 50 & PMTO \\
\hline
\end{tabular}

Where $\mathrm{Si}$ : silicone rubber (PDMS)

PA: Polyamide (PA12)

D: DCP

T: TEMPO

P: PMTO

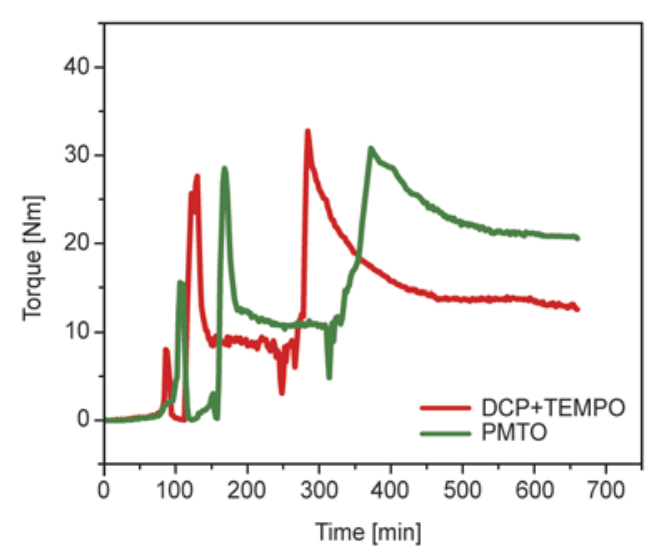

Figure 2. Mixing curves of TPVs cross-linked by different peroxides

dispersion of the rubber phase has taken place in (DCP+TEMPO) cross-linked TPV which has been discussed later in the morphology study. But for PMTO cross-linked TPV, the rate of fall of torque is not so fast like (DCP+TEMPO) cross-linked TPV. Even after few minutes torque has fallen down from 30.76 to $25.56 \mathrm{Nm}$. This implies proper dispersion and distribution of the rubber particles. Therefore from the two curves it can be observed that, at high temperature due to faster decomposition of DCP in presence of TEMPO also, cross-linking efficiency of (DCP+TEMPO) becomes lower and state of cross-linking is also becomes poor. Due to that reason torque falls down steeply. On the other side, due to high thermal stability of PMTO, its state of curing is much better than (DCP+TEMPO) which correlates with the higher torque value during TPV preparation.

\subsection{Morphology study}

Morphology study of two thermoplastic vulcanizates was performed and shown in Figure 3. From the SEM photomicrograph of the two TPVs, it is clear that for the (DCP+TEMPO) cross-linked TPV, cross-linking of the rubber phase has not been taken place fully and wider distribution has not taken place also. (DCP+TEMPO) cross-linked TPV suffers from the faster decomposition of DCP even after the addition of TEMPO, due to the rise of temperature during mixing. Even after addition of TEMPO also scorch safety of DCP increases not so 


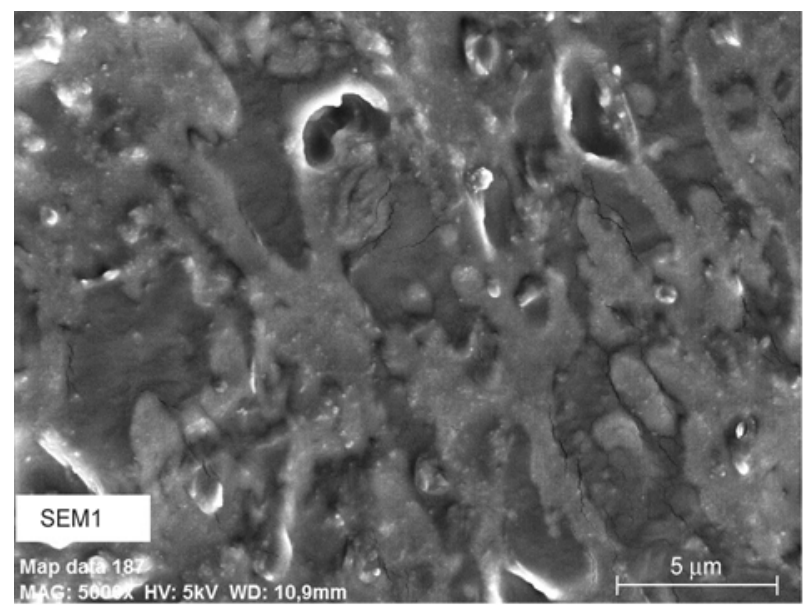

a)

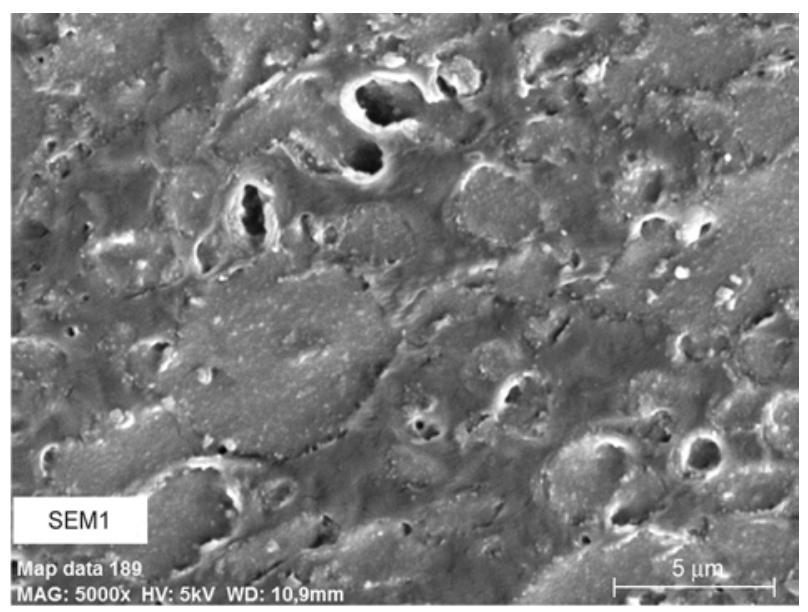

b)

Figure 3. SEM photomicrographs of TPVs cross-linked by a) DCP+TEMPO, b) PMTO

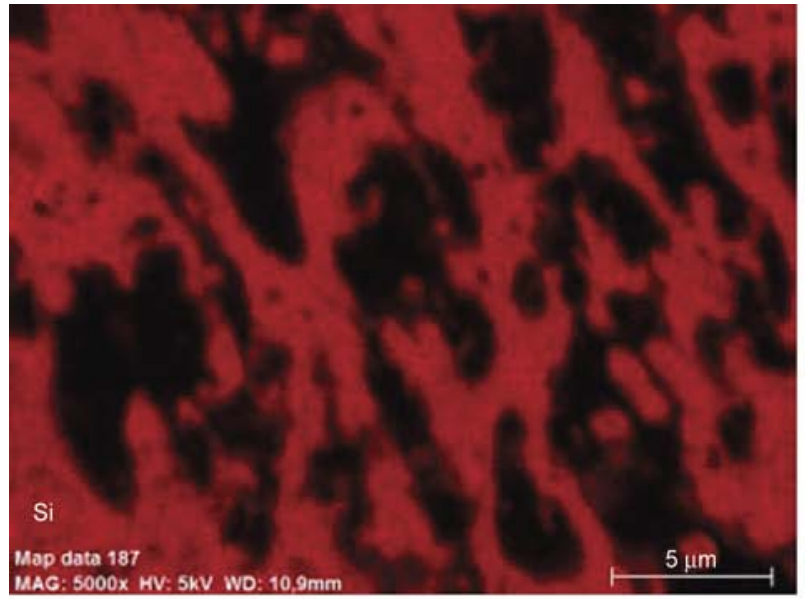

a)

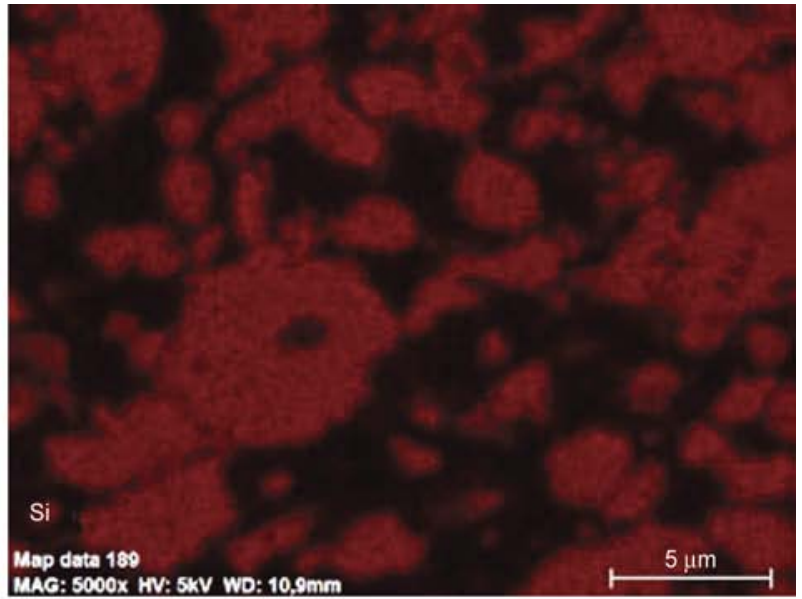

b)

Figure 4. Silicon mapping of TPVs cross-linked by a) DCP+TEMPO, b) PMTO

much which is clear from Table 3. In (DCP+ TEMPO) cross-linked TPV, initially the cross-linking rate of DCP was higher but due to the faster decomposition of DCP at high temperature dispersion and distribution of the rubber phase has not taken place properly which results in a co-continuous phase morphology rather than in the dispersed phase one, as shown in Figure 3a.

On the other hand, PMTO is new, high temperature peroxide which extends the temperature range of cross-linking. Scorch safety time and optimum curing time for PMTO is very high which is shown in Table 3. As a result, faster decomposition of PMTO has not taken place, even after the rise of temperature during mixing. Therefore, though the rate of cross-linking of PMTO is little bit lower than that of (DCP+TEMPO), dispersion and distribution of the rubber phase has taken place properly which results dispersed phase morphology in the final TPV. However, from Figure $3 \mathrm{~b}$ it can also be observed there is more or less wider distribution of the cross-linked rubber particles in the polyamide matrix and the particle size of the rubber phase varies in the 1$4 \mu \mathrm{m}$ range. The same picture can also be observed from the silicon mapping of the consequent TPVs which is shown in Figure 4.

Similar morphology was observed from the atomic force microscopy (AFM) picture of a TPE and TPV system which is shown in Figure 5. From the top view of the TPE and TPV it is clearly seen that in case of TPE the two phase forms the co-continuous structure and there is no peak and hills, which can be seen from the Figure 5a. But for the picture of TPV it can be easily observed that the rubber phase is properly cross-linked and that is why rubber phase has appeared as peaks and hills in the Figure 5b.

\subsection{Mechanical properties}

Mechanical properties of the various TPVs are given in Table 6. From the mechanical properties of 

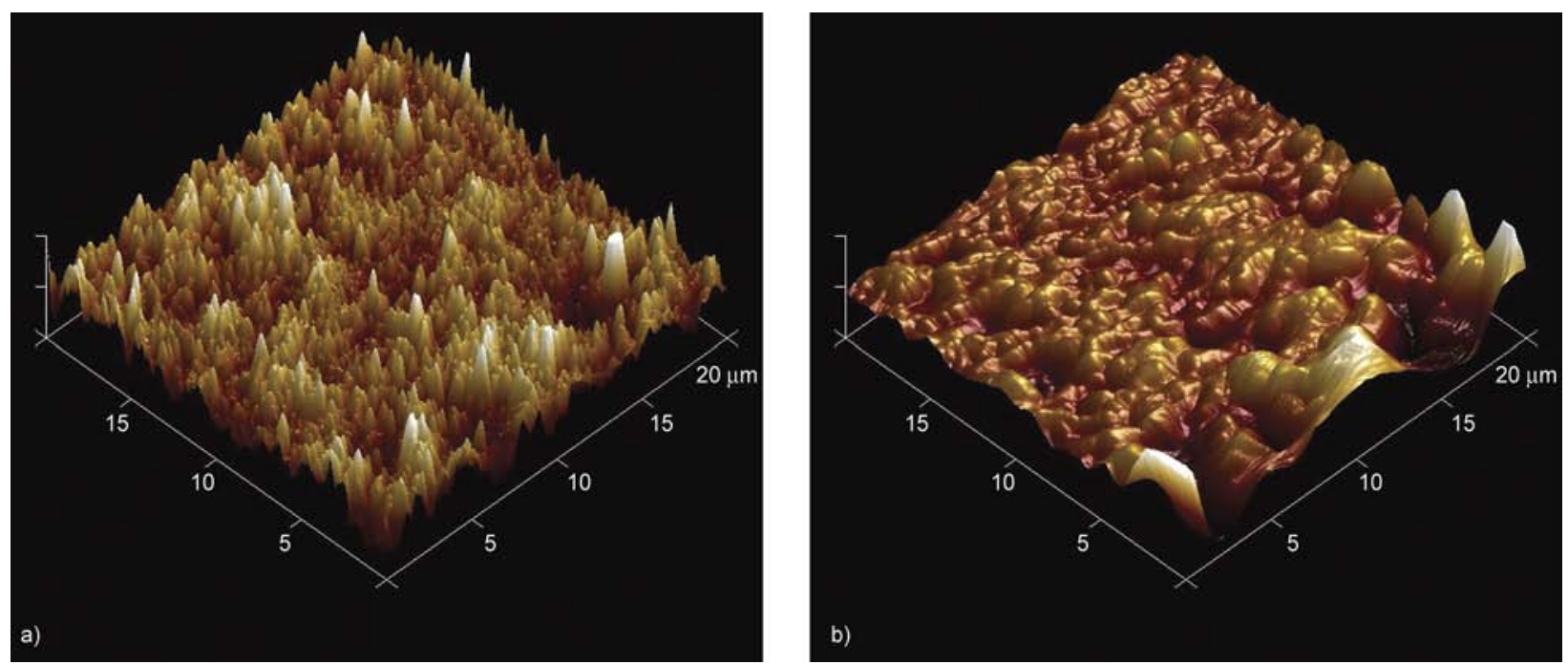

Figure 5. Top view image of a) TPE and b) TPV (PMTO cross-linked)

Table 6. Mechanical properties of the TPVs of PDMS/PA12

\begin{tabular}{|l|c|c|c|c|}
\hline Sample code & $\begin{array}{c}\text { Young's } \\
\text { modulus, E E } \\
{[\mathbf{t} \text { tPa] }}\end{array}$ & $\begin{array}{c}\text { Tensile } \\
\text { strength } \\
{[\mathbf{M P a}]}\end{array}$ & $\begin{array}{c}\text { Elongation } \\
\text { at break } \\
{[\%]}\end{array}$ & $\begin{array}{c}\text { Hardness } \\
\text { [Shore D] }\end{array}$ \\
\hline Si_PA_D_T & $649 \pm 47$ & $19.6 \pm 1.9$ & $51 \pm 8$ & $39 \pm 3$ \\
\hline Si_PA_P & $785 \pm 30$ & $26.5 \pm 0.6$ & $127 \pm 6$ & $59 \pm 4$ \\
\hline
\end{tabular}

the TPVs it can be clearly observed that TPV crosslinked by PMTO gives better result from tensile strength, elongation and hardness point of view. Tensile strength of PMTO cross-linked TPV is 26.5 MPa whereas for the (DCP+TEMPO) crosslinked TPV it is $19.6 \mathrm{MPa}$. Elongation at break of the PMTO cross-linked TPV is $127 \%$ whereas for the (DCP+TEMPO) cross-linked TPV 51\% only. On the other hand, hardness of PMTO cross-linked TPV is 59 Shore D whereas for (DCP+TEMPO) cross-linked TPV it is 39 Shore D. Tension set of PMTO cross-linked TPV samples is $21 \%$. Due to co-continuous phase morphology in (DCP+TEMPO) cross-linked TPV, mechanical properties of (DCP+ TEMPO) cross-linked TPV are poor whereas mechanical properties of PMTO cross-linked TPV are superior because of dispersed phase morphology and wider distribution of the rubber particles. This implies that in presence of PMTO, rubber phase gets fully cross-linked in PMTO cross-linked TPV which correlates with the higher value of overall cross-link density which has been shown later.

\subsection{Dynamic mechanical thermal analysis (DMTA)}

Storage modulus of the two thermoplastic vulcanizates are shown in Figure 6. It can be observed that at relatively low temperature the storage modulus

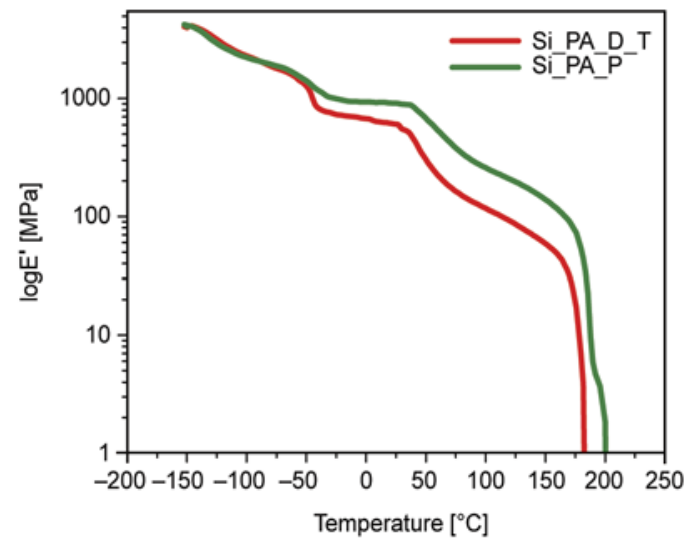

Figure 6. Storage modulus $\left(E^{\prime}\right)$ of TPVs as a function of temperature

$\left(E^{\prime}\right)$ of both the TPVs are almost same. The rubbery plateau region is found between -45 to $+55^{\circ} \mathrm{C}$. From Figure 6, it can be noticed that in the rubbery plateau region storage modulus of PMTO crosslinked TPV are higher than that of the (DCP+ TEMPO) cross-linked TPV. This clearly indicates the higher degree of cross-linking in PDMS rubber phase in PMTO cross-linked TPV over (DCP+ TEMPO) cross-linked one. Even at higher temperature the storage modulus value of PMTO crosslinked TPV is found higher than the (DCP+TEMPO) cross-linked TPV. Therefore, mechanical properties and overall cross-link density of the PMTO crosslinked TPV were found superior to the (DCP+ TEMPO) cross-linked one. Storage modulus and $\tan \delta$ values of all the TPVs were shown in the Table 7. Figure 7 illustrates the tan $\delta$ plot as function of temperature and demonstrates that there are two major transitions: the $T_{\mathrm{g}}$ of PDMS at around $-120^{\circ} \mathrm{C}$ and that of $\mathrm{PA}$ at around $+55^{\circ} \mathrm{C}$. Another transition is at 
Table 7. Storage modulus $\left(E^{\prime}\right)$ and $\tan \delta$ values of TPVs

\begin{tabular}{|l|c|c|c|}
\hline Sample code & $\begin{array}{c}\mathbf{E}^{\prime} \cdot \mathbf{1 0}^{\mathbf{2}} \text { at } \mathbf{2 5} \\
{[\mathbf{M P a}]}\end{array}$ & $\begin{array}{c}\tan \boldsymbol{\delta} \\
\mathbf{a t}-\mathbf{1 2 0}^{\circ} \mathbf{C}\end{array}$ & $\begin{array}{c}\tan \boldsymbol{\delta} \\
\text { at } \mathbf{5 5}^{\circ} \mathbf{C}\end{array}$ \\
\hline Si_PA_D_T & 6.19 & 0.075 & 0.154 \\
\hline Si_PA_P & 9.02 & 0.073 & 0.115 \\
\hline
\end{tabular}

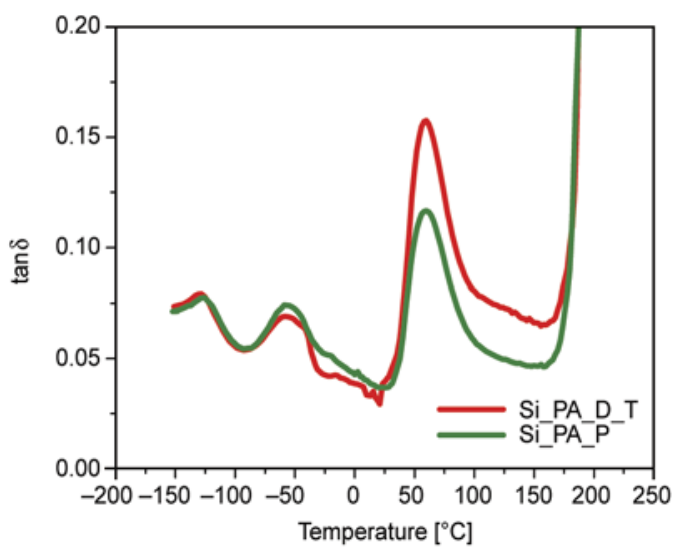

Figure 7. Tan $\delta$ of TPVs as a function of temperature

around $-50^{\circ} \mathrm{C}$, which is the ductile brittle transition temperature of the PDMS. It can also be clearly observed that the $T_{\mathrm{g}}$ of PA12 has been shifted from $55^{\circ} \mathrm{C}$ to the higher value for the TPVs due to interaction between the two phases. The lower $\tan \delta$ value of the PMTO cross-linked TPV at $T_{\mathrm{g}}$ of silicone rubber, indicates the higher cross-linking of the PDMS rubber phase and lesser damping characteristics of the TPVs.

\subsection{Thermogravimetric analysis (TGA)}

Thermogravitograms and derivatograms of neat PDMS, PA12 and TPVs are shown in the Figure 8a and $8 \mathrm{~b}$ respectively and the data are presented in Table 8. From the table, it is clearly observed that the initial decomposition temperature $\left(T_{\mathrm{i}}\right)$ of PDMS is at $476^{\circ} \mathrm{C}$, whereas for the PA12 it is rather low at $380^{\circ} \mathrm{C}$. Similarly the $50 \%$ weight loss temperature for PDMS is $584^{\circ} \mathrm{C}$ whereas for PA12 it is $415^{\circ} \mathrm{C}$

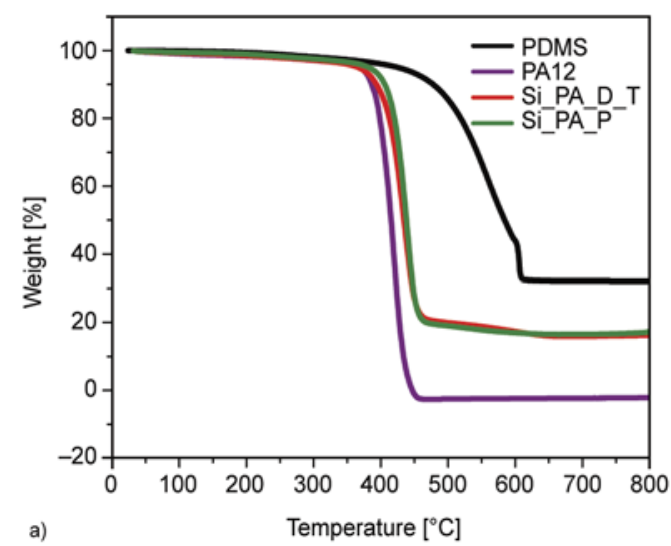

Table 8. TGA data of PDMS, PA12 and TPVs

\begin{tabular}{|l|c|c|c|}
\hline Sample code & $\begin{array}{c}\text { Initial } \\
\text { decomposition } \\
\text { temperature, } \mathbf{T}_{\mathbf{i}} \\
{\left[{ }^{\circ} \mathbf{C}\right]}\end{array}$ & $\begin{array}{c}\mathbf{5 0 \%} \text { weight loss } \\
\text { temperature } \\
{\left[{ }^{\circ} \mathbf{C}\right]}\end{array}$ & $\begin{array}{c}\text { Residue at } \\
\mathbf{6 0 0}^{\circ} \mathbf{C} \\
{[\%]}\end{array}$ \\
\hline PDMS & 476 & 584 & 43.900 \\
\hline PA12 & 380 & 415 & 0.045 \\
\hline Si_PA_D_T & 410 & 436 & 15.250 \\
\hline Si_PA_P & 432 & 465 & 17.980 \\
\hline
\end{tabular}

only. But considering the percentage residue at $600^{\circ} \mathrm{C}$, it can be clearly stated that at $600^{\circ} \mathrm{C}$ PA 12 decomposes fully and that is why percent residue is very less, whereas at $600^{\circ} \mathrm{C}$ the percent residue for PDMS is $43.9 \%$. It indicates that at higher temperature say $600^{\circ} \mathrm{C}$ also decomposition of PDMS does not take place fully and for PDMS there is always higher percentage of residue because of presence of silica filler into the PDMS. Amongst the TPVs, $T_{\mathrm{i}}$ is the highest for the PMTO cross-linked TPV. Similarly $50 \%$ weight loss temperature and $\%$ residue at $600^{\circ} \mathrm{C}$ for the PMTO cross-linked TPV are $465^{\circ} \mathrm{C}$ and $17.98 \%$ respectively, which are $436^{\circ} \mathrm{C}$ and $15.25 \%$ for the (DCP+TEMPO) cross-linked TPV. Thus it can be concluded that the thermal stability of PMTO cross-linked TPV is higher and this has been taken place due to the higher cross-linking efficiency of the PMTO at higher temperature.

\subsection{Melt rheological study}

Complex modulus $\left(G^{*}\right)$ as a function of frequency at $190^{\circ} \mathrm{C}$ for TPVs are shown in the Figure 9. From the figure it can be clearly observed that with increasing frequency the complex modulus $\left(G^{*}\right)$ of the TPVs is increasing. But the increase in complex modulus is maximum in the case of TPV which is crosslinked by PMTO. The complex modulus $\left(G^{*}\right)$ values at a frequency of $100 \mathrm{rad} / \mathrm{s}$ and the complex viscos-

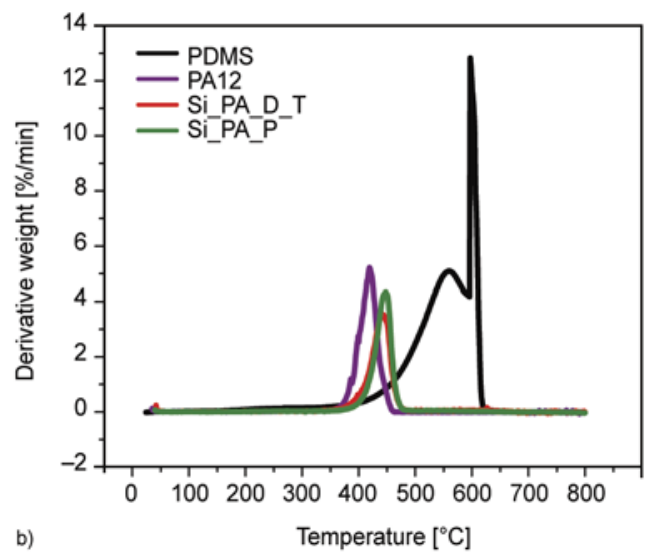

Figure 8. a) Thermogravitograms and b) derivatograms of PDMS, PA12 and TPVs 


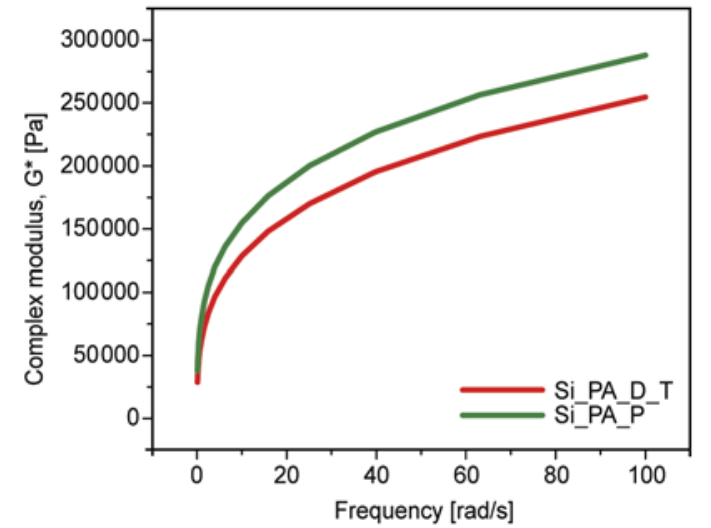

Figure 9. Complex modulus $\left(G^{*}\right)$ of TPVs as a function of frequency at $190^{\circ} \mathrm{C}$

Table 9. Complex modulus $\left(G^{*}\right)$ and complex viscosity $\left(\eta^{*}\right)$ of TPVs

\begin{tabular}{|l|c|c|}
\hline \multicolumn{1}{|c|}{ Sample code } & $\begin{array}{c}\boldsymbol{G}^{*} \cdot \mathbf{1 0}^{\mathbf{5}} \text { at 100 } \mathbf{~ r a d} / \mathbf{s} \\
{[\mathbf{P a}]}\end{array}$ & $\begin{array}{c}\boldsymbol{\eta}^{*} \cdot \mathbf{1 0}^{\mathbf{3}} \text { at } \mathbf{~} \mathbf{~ r a d} / \mathbf{s} \\
{[\mathbf{P a} \cdot \mathbf{s}]}\end{array}$ \\
\hline Si_PA_D_T & 2.55 & 62.50 \\
\hline Si_PA_P & 2.94 & 69.09 \\
\hline
\end{tabular}

ity $\left(\eta^{*}\right)$ values at a frequency of $1 \mathrm{rad} / \mathrm{s}$ are given in the Table 9. From the table also it is clear that the TPV, cross-linked by PMTO has given the maximum value of complex modulus $\left(G^{*}\right)$ which is $2.94 \cdot 10^{5} \mathrm{~Pa}$, higher than the (DCP+TEMPO) crosslinked TPV.

From the Figure 10 it is seen that complex viscosity $\left(\eta^{*}\right)$ of TPVs decreases as a function of frequency, indicating typical pseudoplastic behaviour. It can also be demonstrated that higher cross-linking has taken place in the TPV cross-linked by PMTO. From the figure it is clear that complex viscosity $\left(\eta^{*}\right)$ of the PMTO cross-linked TPV is higher than the (DCP+TEMPO) cross-linked TPV throughout the frequency range. So from the Table 9 also it is clear that the TPV, cross-linked by PMTO has given

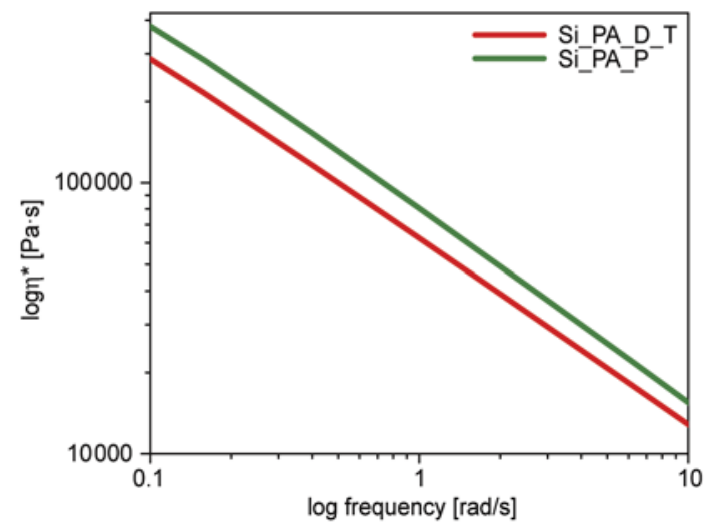

Figure 10. Complex viscosity $\left(\eta^{*}\right)$ of TPVs as a function of frequency at $190^{\circ} \mathrm{C}$ the maximum value of complex viscosity $\left(\eta^{*}\right)$ which is $69.09 \cdot 10^{3} \mathrm{~Pa} \cdot \mathrm{s}$, higher than the $(\mathrm{DCP}+$ TEMPO) cross-linked TPV. So it can be concluded that maximum cross-linking also has been taken place by the TPV which is cross-linked by PMTO and that has been supported also through the determination of overall cross-link density of the TPVs discussed next.

\subsection{Overall cross-link density}

From the Figure 11 it is clearly observed that the overall cross-link density ( $v+$ PA) of the PMTO crosslinked TPV is higher than that of the (DCP+TEMPO) cross-linked TPV. For the TPV which are crosslinked by $(\mathrm{DCP}+\mathrm{TEMPO}),(v+\mathrm{PA})$ value is $17.1 \cdot 10^{-4} \mathrm{~mol} / \mathrm{mL}$. On the other hand, it can be clearly seen that the $(v+\mathrm{PA})$ value of the PMTO cross-linked TPV is $56.8 \cdot 10^{-4} \mathrm{~mol} / \mathrm{mL}$ higher than that of the (DCP+TEMPO) cross-linked TPV. This also implies that in presence of PMTO, cross-linking of the rubber phase has been taken place in the PMTO cross-linked TPV whereas for the (DCP+ TEMPO) cross-linked TPV cross-linking of the rubber phase has not taken place properly.

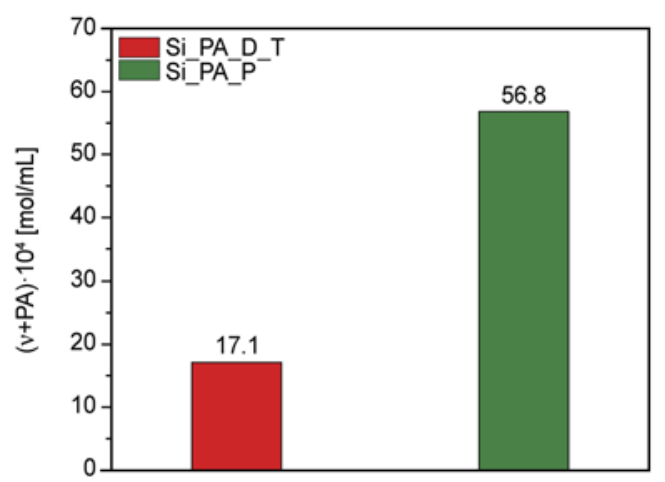

Figure 11. Overall cross-link density of the TPVs

\section{Conclusions}

A detailed study has been made in this investigation to develop a novel TPV based on PDMS and PA12. For the development of TPV three structurally different peroxides (DCP, PMTO and CHP) have been explored and out of these three peroxides PMTO cross-linked TPV gave superior properties from all respective points of view. During dynamic vulcanization PMTO gives a better scorch safety than the other two peroxides. That is why during dynamic vulcanization the dispersion of the rubber particles also takes place properly and the domain size also 
becomes smaller. This is supported by SEM, EDX studies and AFM as well which clearly show that the finer dispersion is only achievable in case of PMTO cross-linked TPV. Moreover, there is evidence that the co-continuous non-reactive blend morphology has been changed into a dispersed one with cross-linked PDMS-domains embedded in the PA12 matrix. Accordingly mechanical properties of the PMTO cross-linked TPV are superior than the (DCP+TEMPO) cross-linked TPV. This can again be attributed to the presence of fine dispersed crosslinked PDMS domains in case of the dynamic vulcanization with PMTO. This is reflected also in the dynamic mechanical properties, both in the solid as well in the molten state, where the PMTO based TPV always showed a higher storage modulus in junction with lower $\tan \delta$ values. These findings indicate also higher overall cross-link density of the PMTO cross-linked TPV in comparison to the (DCP+ TEMPO) based one. Accordingly the thermal stability of the PMTO based TPV is also higher, as substantiated by TGA-investigations. Considering all the results, it can be concluded that for further development of PDMS/PA12 based TPV, PMTO is a suitable peroxide.

\section{Acknowledgements}

We thank Mrs. M. Auf der Landwehr (IPF Dresden) for the morphology characterization by means of SEM-EDX. Thanks to D. Willink of Akzo Nobel Polymer Chemicals B.V. (Amersfoort, NL) for providing free samples of Trigonox ${ }^{\circledR}$ 311. Also thanks to Dr. A. Das, Dr. A. Leuteritz, Prof. U. Wagenknecht, R. Jurk and H. Kunath for valuable discussions and support.

\section{References}

[1] Karger-Kocsis J.: Thermoplastic rubbers via dynamic vulcanization. in 'Polymer blends and alloys' (eds.: Shonaike G. O., Simon G. P.) Marcel Dekker, NewYork 125-153 (1999).

[2] Babu R. R., Naskar K.: Recent developments on thermoplastic elastomers by dynamic vulcanization. Advances in Polymer Science, 239, 219-247 (2011).

DOI: $10.1007 / 12 \quad 201097$

[3] Paul D. R., Bucknall C. B.: Polymer blends. Wiley, New York (2000).

[4] Utracki L. A., Favis B. D.: Polymer alloys and blendsThermodynamics and rheology. Hanser, Munich (1990).

[5] De S. K., Bhowmick A. K.: Thermoplastic elastomers from rubber plastic blends. Horwood, London (1990).
[6] Holden G., Legge N. R., Schroeders H. E.: Thermoplastic elastomer: A comprehensive review. Hanser, Munich (1987).

[7] Bousmina M., Muller R.: Rheology/morphology/flow conditions relationships for polymethylmethacrylate/ rubber blend. Rheologica Acta, 35, 369-381 (1996). DOI: $10.1007 / \mathrm{BF} 00403538$

[8] Abdou-Sabet S., Puydak R. C., Rader C. P.: Dynamically vulcanized thermoplastic elastomers. Rubber Chemistry and Technology, 69, 476-494 (1996). DOI: $10.5254 / 1.3538382$

[9] Gessler A. M., Haslett W. H.: Process for preparing a vulcanised blend of crystalline polypropylene and chlorinated butyl rubber. U.S. Patent 3037954, USA (1962).

[10] Fisher W. K.: Thermoplastic blend of partially cured monoolefin copolymer rubber and polyolefin plastic. U.S. Patent 3862106, USA (1973).

[11] Coran A. Y., Das B., Patel R. P.: Thermoplastic vulcanizates of olefin rubber and polyolefin resin. U.S. Patent 4130535, USA (1978).

[12] Coran A. Y., Patel R.: Rubber-thermoplastic compositions. Part I. EPDM-polypropylene thermoplastic vulcanizates. Rubber Chemistry and Technology, 53, 141150 (1980).

DOI: $10.5254 / 1.3535023$

[13] Naskar K., Noordermeer J. W. M.: Influence of various peroxides in PP/EPDM thermoplastic vulcanizates at varied blend ratios. Journal of Elastomers and Plastics, 38, 163-180 (2006). DOI: $10.1177 / 0095244306060215$

[14] Naskar K., Noordermeer J. W. M.: Dynamically vulcanized PP/EPDM blends: Multifunctional peroxides as crosslinking agents - Part I. Rubber Chemistry and Technology, 77, 955-971 (2004). DOI: $10.5254 / 1.3547862$

[15] Naskar K., Gohs U., Wagenknecht U., Heinrich G.: PP-EPDM thermoplastic vulcanisates (TPVs) by electron induced reactive processing. Express Polymer Letters, 3, 677-683 (2009). DOI: $10.3144 /$ expresspolymlett.2009.85

[16] Basuli U., Chaki T. K., Naskar K.: Influence of Engage ${ }^{\circledR}$ copolymer type on the properties of Engage ${ }^{\circledR} /$ silicone rubber-based thermoplastic dynamic vulcanizates. Express Polymer Letters, 2, 846-854 (2008). DOI: $10.3144 /$ expresspolymlett.2008.99

[17] Chatterjee K., Naskar K.: Development of thermoplastic elastomers based on maleated ethylene propylene rubber (m-EPM) and polypropylene (PP) by dynamic vulcanization. Express Polymer Letters, 1, 527-534 (2007).

DOI: $10.3144 /$ expresspolymlett.2007.75

[18] Babu R. R., Singha N. K., Naskar K.: Interrelationships of morphology, thermal and mechanical properties in uncrosslinked and dynamically crosslinked PP/ EOC and PP/EPDM blends. Express Polymer Letters, 4, 197-209 (2010). DOI: $10.3144 /$ expresspolymlett.2010.26 
[19] Rajeshbabu R., Gohs U., Naskar K., Mondal M., Wagenknecht U., Heinrich G.: Electron-induced reactive processing of poly(propylene)/ethylene-octene copolymer blends: A novel route to prepare thermoplastic vulcanizates. Macromolecular Materials and Engineering, 297, 659-669 (2012).

DOI: $10.1002 /$ mame.201100209

[20] McNally T., McShane P., Nally G. M., Murphy W. R., Cook M., Miller A.: Rheology, phase morphology, mechanical, impact and thermal properties of polypropylene/metallocene catalysed ethylene 1-octene copolymer blends. Polymer, 43, 3785-3793 (2002). DOI: $10.1016 / \mathrm{S} 0032-3861(02) 00170-2$

[21] Da Silva A. L. N., Rocha M. C. G., Coutinho F. M. B., Bretas R., Scuracchio C. J.: Rheological, mechanical, thermal, and morphological properties of polypropylene/ethylene-octene copolymer blends. Journal of Applied Polymer Science, 75, 692-704 (2000).

DOI: $10.1002 /($ SICI) 1097-4628(20000131)75:5<692:: AID-APP12>3.0.CO;2-Y

[22] Giri R., Naskar K., Nando G. B.: Effect of electron beam irradiation on the structure property relationship of LLDPE and PDMS rubber blends. Rubber Fibres Plastics International, 6, 97-107 (2011).

[23] Rajeshbabu R., Gohs U., Naskar K., Thakur V., Wagenknecht U., Heinrich G.: Preparation of polypropylene (PP)/ethylene octene copolymer (EOC) thermoplastic vulcanizates (TPVs) by high energy electron reactive processing. Radiation Physics and Chemistry, 80, 1398-1405 (2011).

DOI: $10.1016 /$ j.radphyschem.2011.07.001

[24] Mani S.: Fundamentals aspects of crosslinking control of PDMS rubber at high temperatures using Tempo Nitroxide. PhD thesis, Claude Bernard University Lyon 1, France (2011).

[25] Chang C-L., Don T-M., Lee H. S-J., Sha Y-O.: Studies on the aminolysis of RTV silicone rubber and modifications of degradation products. Polymer Degradation and Stability, 85, 769-777 (2004).

DOI: $10.1016 /$ j.polymdegradstab.2003.12.001
[26] Mani S., Cassagnau P., Bousmina M., Chaumont P.: Morphology development in novel composition of thermoplastic vulcanizates based on PA12/PDMS reactive blends. Macromolecular Materials and Engineering, 296, 909-920 (2011). DOI: $10.1002 /$ mame. 201000406

[27] Mark J. E., Allcock H. R., West R.: Inorganic polymers. Oxford University Press, New York (2005).

[28] Santra R. N., Mukunda P. G., Nando G. B., Chaki T. K.: Thermogravimetric studies on miscible blends of ethylene-methyl acrylate copolymer (EMA) and polydimethylsiloxane rubber (PDMS). Thermochimica Acta, 219, 283-292 (1993).

DOI: 10.1016/0040-6031(93)80505-5

[29] Arkema: Market research showed that Rilsan PA11 and Rilsan PA12 are highly valued by major car OEMs. p2 (2007).

[30] Dorn M.: Modification of molecular weight and flow properties of thermoplastics. Advances in Polymer Technology, 5, 87-97 (1985). DOI: $10.1002 / \mathrm{adv} .1985 .060050203$

[31] Mani S., Cassagnau P., Bousmina M., Chaumont P.: Rheological modelling of the free-radical crosslinking of PDMS rubber in the presence of TEMPO nitroxide. Polymer, 51, 3918-3925 (2010).

DOI: 10.1016/j.polymer.2010.06.029

[32] Mani S., Cassagnau P., Bousmina M., Chaumont P.: Cross-linking control of PDMS rubber at high temperatures using TEMPO nitroxide. Macromolecules, 42, 8460-8467 (2009). DOI: $10.1021 / \mathrm{ma901521 \textrm {v }}$

[33] Alvarez Grima M. M.: Novel co-agents for improved properties in peroxide cure of saturated elastomers. PhD Thesis, University of Twente, Enschede (1992). 